\title{
Drivers that Impact the Merchants' Repeat Intention for Group Deal Promotions
}

\author{
Nina Angelovska \\ Macedonian E-commerce Association, North Macedonia \\ nina.angelovska@gmail.com \\ Sasho Josimovski \\ University 'Ss. Cyril and Methodius,' North Macedonia \\ saso.josimovski@eccf.ukim.edu \\ Lidija Pulevska Ivanovska \\ University 'Ss. Cyril and Methodius,' North Macedonia \\ lidija.pulevska@eccf.ukim.edu
}

\begin{abstract}
The purpose of this study is to investigate the drivers affecting merchant's intention to repeat group deal offers and use the group buying site as a promotional tool. The research is done based on secondary and primary data collection. Primary data was collected through a questionnaire aimed at businesses that had completed a daily deal promotion. Tobit model was employed to analyze data. The results show that merchants' intention to repeat offers depends on profitability of the deals output, spending beyond the coupon, new customers brought by the deal, and there is diversity across different categories of businesses. Findings of this study can be useful to group buying companies to improve their business to small- and medium-sized businesses considering a daily deal promotion.
\end{abstract}

Key Words: retailers, profitability, marketing, tobit model, group buying model, promotions, Macedonia

JEL Classification: M31, M21

https://doi.org/10.26493/1854-6935.17.221-238

\section{Introduction}

The advent of electronic commerce has led to the creation of many new business models for Internet-based selling (Kauffman and Wang 2001). The Web has enjoyed tremendous growth in consumer spending as a channel that is characterized by convenience, wide product selection, and easy comparison shopping (Kauffman and Wang 2002). The business model of group buying was introduced by the company Groupon in 2008. It represents a win-win for both the retailers and end-customers; savings for the end-customers and new customers for the retailers. As the group 
buying sites are intermediaries between retailers and final users, they have to focus twofold: to the retailers and the end-users. As two-sided markets, daily-deal platforms allow merchants to attract new consumers via discounts (Subramanian and Rao 2016). Retailers are the core of the group deal sites business model because they produce the product that the site markets. Acquiring more retailers diversifies the list of products they can market, which allows them to attract more paying subscribers and increase revenues. However, what is more important than the acquisition of featured retailers is the retention thereof, or their intention to repeat deal offers. The acquisition growth will undoubtedly slow, as there can only be a finite number of retailers willing to use the service, especially in the small emerging countries. Consequently, the majority of revenues must come from repeat retailers.

The model was so successful and enjoyed massive growth in 2010 and is growing rapidly in emerging economies (Erdogmus and Cicek 2011). Hundreds of daily deal sites have been launched. As an online promotion form, group-buying model has low barriers to entry therefore it can be quickly launched but evidence show that it can be as quickly closed due to fierce competition. A significant number of launched group buying sites shut down, merged with other sites, or changed their business models drastically (Taulli 2012; Heussner 2012; Reisinger 2011; Geron 2011).

The CEO of Groupon India, Ankur Warikoo, claims that the lack of focus on the merchants is the main reason for this (TechCircle 2013). Despite these upheavals, however, the industry's market leaders have remained unchanged and continued to grow impressively. For instance, Groupon acknowledged that merchant retention was integral to revenue growth and achieving profitability (Mazen 2012). It is often difficult and impossible, for small and medium sized enterprises, to place properly their products in customers' minds due to the shortage of capital and resources (Gilmore and Grant 2001).

Many challenges are posed to the new promising model of group buying via daily deals, thus there is need to understand what affects the merchant's decision when evaluating its deal effectiveness and decision to repeat the promotion. With this overall concern in mind, this paper examines the dependency of merchant's deal repeat intention across several factors including new customers acquired from the deal; customer's spending beyond coupon face value and repeat customers and company characteristics as well.

The remainder of this paper is organized as follows. Review of the re- 
lated literature is presented in the second section. In the third section summary of Grouper.mk and its market position is given. The fourth section presents the methodology of the survey and data collection and analysis. In the fifth section, the results are analyzed. The sixth section states the limitations of this research and finally the seventh section concludes and discusses the issue of sustainability of the deal sites promotion on long term and provide specific suggestions for the deal sites for creating the offers that will satisfy the drivers for repeat offers.

\section{Literature Review}

Beyond the academic work on voucher discounts, a well-established literature explores the advertising and pricing of experience goods, i.e. goods for which some characteristics cannot be observed prior to consumption (Nelson 1970; 1974). A substantial literature has observed that selective discounting provides opportunities for price discrimination. For example, in the setting of Varian (1980), firms engage in promotional pricing in order to attract larger market segments. Similar work illustrates how promotions may draw new customers (Blattberg and Neslin 1990), and lead those customers to become relational customers (Dholakia 2006). These results have been found to motivate the use of coupons, especially cents-off coupons (Cremer 1984; Narasimhan 1984). Generous discounts generate more sales from group buying customers (Grandhi, Chugh, and Wibowo 2016). The online group buying act is characterized by the dual value creation philosophy of marketing (Kotler and Armstrong 2009) that both sellers and buyers benefit through it (Anand and Aron 2003). Benefits for buyers are more than obvious because on the group buying sites end customers gain great discounts (Stulec and Petljak 2010). Cao, Hui, and $\mathrm{Xu}$ (2018) found that the offering of discounts should be tied to consumers' confidence in product quality, meaning a one-size-fits-all strategy will not be optimal. The main category of the deal industry in the beginning was the services but soon the goods became very popular as well as the travel deals, imposing the categorization of the deals in 3 main categories: services, goods and travel. Group buying websites' customers are computer literate persons, mostly younger aged who do not have an aversion towards electronic commerce and are mostly members of social networks (Stulec, Petljak, and Vouk 2011).

Benefits for sellers are harder to define unambiguously because they are not exclusively of a financial nature. First, it is important to mention that the group buying websites are an excellent way of promotion 
(Stulec and Petljak 2010). Furthermore, this form of promotion allows companies to reach new customer segments that are more likely to notice an advertisement on a computer screen than in printed form because of their lifestyle (Stulec and Petljak 2010). Benefits are especially great for small businesses that cannot afford advertising through mass media, so group-buying websites can be seen as an excellent way of familiarizing potential customers with products and services of small businesses (Stulec and Petljak 2010). Understanding group buying as an innovative market niche, small and medium enterprises (SMEs) make an attempt to cooperate with particular buying services looking for their sources of competitive advantage in this way (Bilinska-Reformat and Reformat 2011).

The claims and frequent comments about group buying and local deal sites such as Groupon having lost their appeal and are unsustainable were mostly toward its effectiveness for the merchants (Bazilian 2011; Guy 2012; Kamenec 2012; Li, 2012). Groupon's previously reported waiting list of 35,000 businesses suggests that many businesses are eager to experience the value of group buying deals (Sherr 2010); however, group buying deals are not a guarantee of success for small businesses. Articles in the popular press and elsewhere have questioned the value for small businesses, pointing out that the costs of offering some deals cannot be covered by the revenue from deals sold (Vacanti 2011). To give answers to these claims literature has provided empirical evidence on the impact and structure of voucher discounting, measuring merchants' uses of vouchers and consumers' responses. Dholakia (2010) surveys businesses that offered Groupon discounts, finding that some business owners speak glowingly of Groupon, while others regret their voucher promotions. Byers, Mitzenmacher, and Zervas (2012) study the dynamics of discount voucher sales as well as the impact of voucher coupon use on Yelp ratings. Gupta et al. (2012) present complementary findings based on survey evidence, characterizing the types of merchants most likely to profit from offering vouchers.

Groupon has claimed that $97 \%$ of businesses using its service want to be featured again. But an independent study estimates repeat intent at only $48 \%$ (Dholakia 2010). For many small and medium-sized businesses, particularly for ones that are new or struggling, hordes of new customers flocking in because of a social promotion may seem particularly appealing during times when consumers have cut back on so many products and services (Dong-Hun 2009; Kotecha, Leibowitz, and MacKenzie 2008). 
Some prior research also supports the effectiveness of price promotions in drawing new customers to businesses (Walters and MacKenzie 2008). Furthermore, as Greenleaf (1995) has observed, one powerful reason that firms use price promotions is that they can increase profits.

\section{Grouper Summary}

In Macedonia, group-buying websites emerged in 2011 and Grouper was the first one launched in January. Online group buying quickly became a bright spot in the mainland of e-commerce market. It nurtured a group of online shoppers and speeded up the development of the e-commerce market in Macedonia. Grouper is not just the first online group buying site on the Macedonian market, but is leader in the e-commerce industry holding 40\% of the market share in Republic of Macedonia in 2012 and 2013 (see http://www.grouponworks.com). The development of the industry is similar as the global trends mentioned above; many group deal sites opened and many of them have shut down after one year of operation.

By this time, a significant number of local businesses have tried running daily deal promotions, and many of them have run multiple ones.

Over the years Grouper kept its leading position by focusing both on merchants and end-customers. The number of customers has grown over the years and amounts 95.000 in 2014.

The number of new merchants per month, as well as the published deals is in progression since the launch of Grouper. While the number of deals published increases with tremendous rate over the years, the number of new merchants starting cooperation keeps a steady increase rate of about $35 \%$ per year (figure 1). The increase rate in the number of deals published amounts about $100 \%$ on yearly bases which indicates a high deal frequency by existing merchants.

\section{Methodology}

The research is done based on secondary and primary data collection. Internal database of group buying site Grouper, as a good starting point is analyzed, particularly the number of featured promotions each retailer offered. Grouper retailers' internal database is used to quantify the repetition rate. The data analyzed covered the period between January 2011 and July 2014. The number of new retailers by year, category and number of featured deals were examined. Out of total 1065 retailers that offered promotion at least once on Grouper in the period between January 2011 


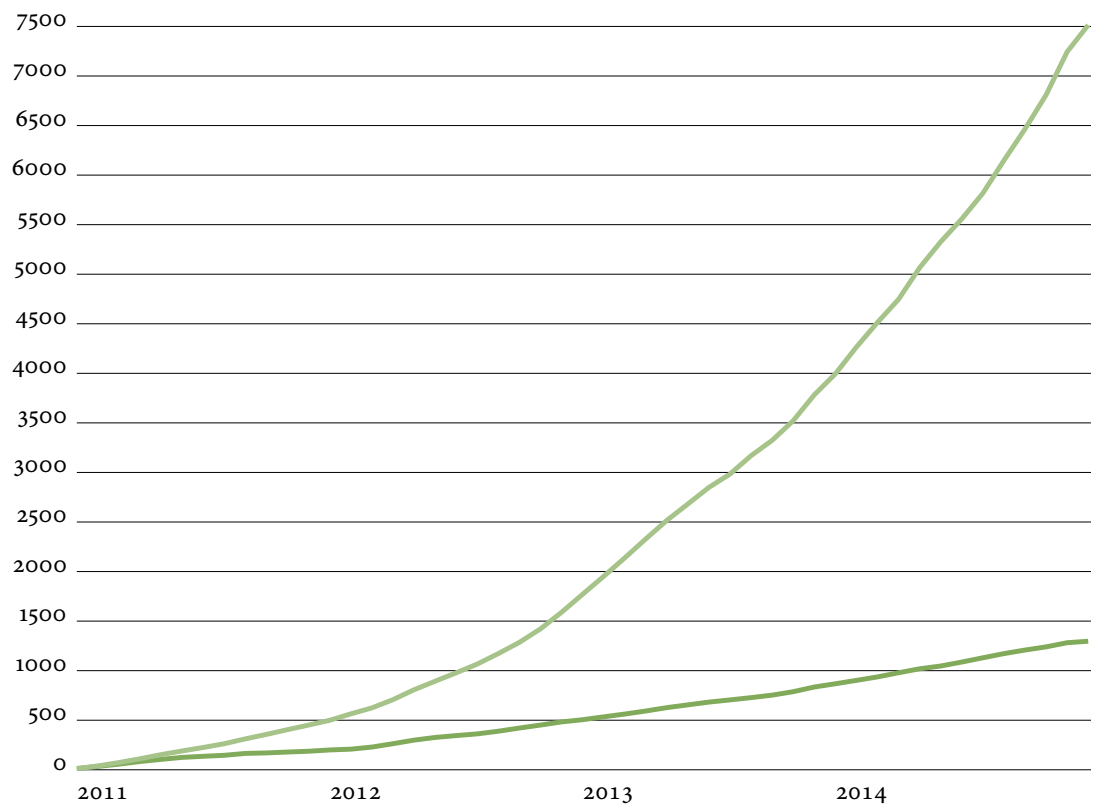

FIGURE 1 Grouper's Growth of Daily Deals Published and New Merchants (January 2011-January 2015)

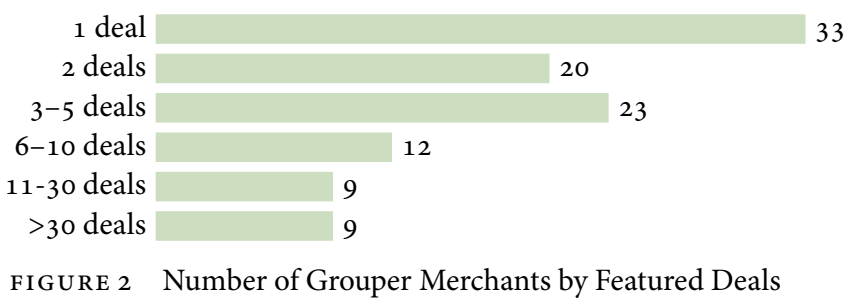

and July 2014, 60\% had promotions running more than once. However the number of retailers with only one deal promotion has to be corrected because of two reasons: (1) the number of retailers that closed their business and (2) the number of retailers that had their first promotion offered in the recent period, because of the short time period for being able to run a second promotion. Considering these corrections, $67 \%$ of retailers running Grouper promotions were repeat retailers (figure 2).

The industry that has the lowest repetition rate is Food and Drink. From 12 retailer's categories (food and drink, beauty, education, automobile, children, culture, sport and entertainment, health, travel, products and miscellaneous) restaurants and café bars account for $20 \%$ of the re- 
tailers that offered only one promotion. On the other hand two categories account for $70 \%$ of the retailers that offered over 30 deals. One is Products, which is logical because one company offered many different products at one time. The second category, which deserves more attention, that participates with $36 \%$ of the retailers with highest repetition rate is the Beauty, particularly Beauty Salons and Spas. These findings coincide with Dholakia (2010), who found that restaurants seemed to be disproportionate failures when it came to Groupon deals while spas were disproportionate winners.

Primary data were collected through an online field survey of businesses that had completed a daily deal promotion with Grouper in the period between January 2013 and June 2014. Aiming to quantify precisely the percentage of the repetition rate of the retailers, attention is given to the retailers that offered only one deal and the selection of the surveyed companies was done: (1) Companies that started cooperation and offered their first deal since May 2014 were extracted from the total number of retailers with one deal offered, because of the short time period for possible second deal; (2) The number of companies that shut down the business was taken out of the final number of retailers that cooperated only once.

The questionnaire was developed via pilot study: (1) A small group of four businesses that had recently run Grouper promotions are called and their owners interviewed to gain a qualitative understanding of their experience with the promotion. (2) The questionnaire was tested within the same group of companies and suggested comments were implemented.

The questionnaire was in Macedonian language and consisted of $3 \mathrm{sec}-$ tions. The first section was consisted of general demographic data for the company: field of operation, years of operation, size and previous promotional tools used; and general information for the Grouper promotional deal: number of featured deals, average regular price and\% of discount. The second and third sections were conditional and based on the answer of the last question of the first section. The retailer that featured deals only on Grouper replied to the further questions in the Section 2 and the retailer that offered promotions on other sites as well replied to the questions in Section 3. In Section 2 and 3 the retailers were asked questions about the particular deals they had run: How merchants value the performance of the offered deals to Grouper compared to other group buying sites measured in: profitability, number of new customers, returning customers from the deal promotion, how much customers' spend beyond face value and the redemption rate of the coupons. Each one is discussed 
in details below. If the retailer runs deals only via Grouper he got the questions for the particular Grouper deals and if he had cooperated with more deal sites he got the same questions except he had to reply answers in a grid comparing Grouper and the other site they were featured on.

An email to 535 grouper businesses partners was sent from the official Grouper contact mail.

Two weeks later, a second e-mail was sent to the companies thanking those who responded and reminding the rest to answer the questionnaire. The study was conducted for a period of three weeks in July. It was closed with 105 completed responses, resulting in response rate of around $20 \%$.

To analyze the collected data quantitative research methods are applied. Descriptive statistics is used to describe and compare the data. The determinants of whether to repeat offers or not are considered to be the identical and empirically, the tobit model was employed to estimate the factors that will drive merchant intention to repeat the deal offers or not. Thus, the decision-making process is considered to be dual where the dependent variable measures the probability of the merchant intention to repeat the offers on the group buying site. So the model is constructed to investigate: What are the drivers that will influence merchants' intention to repeat offers to group buying site? Three broad sets of factors influencing merchants 'repeat intention were considered as independent variables: deals output characteristics, firm characteristics, and deals characteristics. The hypotheses to be tested with the model are:

$\mathrm{H} 1$ Deals output characteristics impact the intention of the merchants to do repeat offers on the group buying site.

H1.1 Profitability impacts the intention of the merchants to do repeat offers on the group buying site.

$\mathrm{H} 1.2$ Repeat customers impact the intention of the merchants to do repeat offers on the group buying site.

H1.3 Spending beyond the coupon impacts the intention of the merchants to do repeat offers on the group buying site.

H1.4 New customers impact the intention of the merchants to do repeat offers on the group buying site.

H1.5 Nonredemption impacts the intention of the merchants to do repeat offers on the group buying site.

$\mathrm{H} 2$ Firms characteristics impact the intention of the merchants to do repeat offers on the group buying site. 
H 2.1 Number of employees impact the intention of the merchants to do repeat offers on the group buying site.

$\mathrm{H} 2.2$ Company category impacts the intention of the merchants to do repeat offers on the group buying site.

$\mathrm{H} 2.3$ Type of the promotion company does impacts the intention of the merchants to do repeat offers on the group buying site.

$\mathrm{H} 2.4$ Firm age impacts the intention of the merchants to do repeat offers on the group buying site.

$\mathrm{H} 3$ Deals characteristics impact the intention of the merchants to do repeat offers on the group buying site.

H3.1 Number of sold coupons impacts the intention of the merchants to do repeat offers on the group buying site.

H3.2 Discount of regular price impacts the intention of the merchants to do repeat offers on the group buying site.

Following Greene (2003), the general specification for the tobit specification is:

$$
\begin{aligned}
y_{i}^{*}= & x_{i}^{\prime} \beta+\sigma \varepsilon_{i} \\
y_{i}= & \begin{cases}0 & \text { if } y_{i}^{\star} \leq \mathrm{o} \\
y_{i}^{*} & \text { if } y_{i}^{*}>\mathrm{o}\end{cases} \\
& \varepsilon \sim N\left(\mathrm{o}, \sigma^{2}\right)
\end{aligned}
$$

where $y_{i}$ equals zero implies that the firm does not intent to repeat deals, while $y_{i}$ equals $y_{i}^{*}$ implies that the firm intents; $i=1,2, \ldots, N$ firms; $x_{i}$ denotes the $1 \times(k+1)$ vector of observed explanatory variables describing: Deals output characteristics; Firm characteristics and Offered deals characteristics. $\beta$ represents the corresponding $(k+1) \times 1$ vector of coefficients to be estimated; and $\varepsilon_{i}$ are the error terms that are independently and individually distributed (iid) over the whole sample with a mean of $\mathrm{o}$ and variance $\sigma^{2}$.

\section{Data Analysis and Results}

The analysis is based on a total of 105 responses of Grouper Merchants that offered deal between January 2013 and June 2014. Around 40\% of the responses are found to be in education and health category. Least responses are given by category Jewelry and Fashion. 
Participated companies are mostly small or half with 3-5 employees, and $13 \%$ over 20 employees. Over $50 \%$ of the participants are companies over 5 years existence and the other half is bellow. $85 \%$ of the participated companies have repetition rate, even $22 \%$ are with more than 10 deals. Considering the use of this new promotional tool, Macedonian companies participating in the survey use social media and group deal sites mostly (44\%), and least Radio and $\mathrm{TV}$.

According to responses $45 \%$ of the companies are loyal to Grouper, and $55 \%$ were running deals on other group buying sites.

The results of the estimated coefficients using equation (1) are presented in table 1 . Before the interpretation of empirical results, a brief discussion regarding diagnostic tests even though such tests are not welldeveloped for tobit model is provided. According to the pseudo $R^{2}$ measure of the overall fit, and the LR $\chi^{2}$ and Prob $>\chi^{2}$ measures of the joint and partial significance of the parameters the model estimations perform well. As shown in table 1, the results in the last column present the expected correlations of the independent variables with the dependent variable: merchants' intention to repeat offer.

Strong support in the model is found for the correlation between merchants' intention to repeat offers and characteristics of the output of deals redemption, namely the profitability of the deals output, followed by the spending beyond the coupon. Also positive correlation is found or it is important for the merchants is new customers brought to the business.

Statistically significant (at $1 \%$ significance level) support is found for H1.3. Spending beyond the coupon face value is useful in assessing a group deal promotion's success because it generates revenue for companies. Beside of getting new customers in the door, as the goal of the promotion the expectations are that they will spend beyond its coupons' value. Small and medium-sized businesses across a range of industries were asked to declare the percentage of customers that spend beyond the group deal's value. $45 \%$ of the participants running Grouper promotions reported o$10 \%$ of the customers spending beyond coupons' face value and $34 \%$ noted spending customers between $11-25 \%$. Table 2 shows percentage of spending beyond the deal promotion face value on Grouper and on the other group sites. $55 \%$ of the respondents running Grouper promotions had 10\% of the customers that spent beyond coupons' value vs. $39 \%$ on the other group sites.

As purpose of group buying promotions is to bring customers to doors of the company and encourage trial of a new product, or of an existing 
TABLE 1 The Estimated Determinants of Intention for Repeat Offers

\begin{tabular}{|c|c|c|c|c|}
\hline Category & Variables & Coeff. St & Std. error & Expected sign \\
\hline \multirow{5}{*}{$\begin{array}{l}\text { Deals output } \\
\text { characteristics }\end{array}$} & Profitability & $39.02^{*}$ & $(24.01)$ & Positive \\
\hline & Repeat customers & -1.22 & $(21.65)$ & Ambiguous \\
\hline & Spending beyond the coupon & $7.20^{* * *}$ & $(27.99)$ & Positive \\
\hline & New customers & $2.15^{\star *}$ & $(25.61)$ & Positive \\
\hline & Nonredemption & 0.01 & $-5,131$ & Ambiguous \\
\hline \multirow{4}{*}{$\begin{array}{l}\text { Firm } \\
\text { characteristics }\end{array}$} & Number of employees & -0.157 & $-6,665$ & Nonlinear \\
\hline & Company category & $40.66^{\star}$ & $(23.33)$ & Positive \\
\hline & Type of promotion firm does & -139.2 & (90.55) & Ambiguous \\
\hline & Firm age & $-8,980$ & $(21.33)$ & Ambiguous \\
\hline \multirow{10}{*}{$\begin{array}{l}\text { Deals } \\
\text { characteristics }\end{array}$} & Number of sold coupons & 2,654 & $(18.17)$ & Positive \\
\hline & Discount of regular price & 6,307 & $(38.46)$ & Negative \\
\hline & Constant & -147.0 & $(121.5)$ & \\
\hline & Sigma & $46.60^{* * *}$ & $*-9,002$ & \\
\hline & Observations & 105 & & \\
\hline & Uncensored observations & 37 & & \\
\hline & $\operatorname{LR} \chi^{2}(16)$ & 75.61 & 113.84 & \\
\hline & Prob $>\chi^{2}$ & 0.0001 & 0.001 & \\
\hline & Pseudo $R^{2}$ & 0.26 & 0.79 & \\
\hline & Log likelihood & -108.09 & -14.68 & \\
\hline
\end{tabular}

TABLE 2 Percentage of Spending Beyond the Deal Promotion Face Value on Grouper and on the Other Group Sites (\%)

\begin{tabular}{lrr}
\hline Percentage of customers & $(1)$ & $(2)$ \\
\hline $0-10$ & 45,00 & 61,00 \\
$11-25$ & 34,00 & 21,00 \\
$26-50$ & 13,00 & 11,00 \\
$51-75$ & 6,00 & 5,00 \\
Above 75 & 2,00 & 2,00 \\
\hline
\end{tabular}

NOTES Column headings are as follows: (1) Grouper, (2) other deal platforms.

product, the most important is how many among them are first time customers. Hypothesis H1.4. is supported at 5\% significance level. New customer acquisition efficacy is a key driver in group buying promotion evaluation, because if the existing customers come with coupons for the 
TABLE 3 New Customer Acquisition on Grouper and on the Other Group Sites (\%)

\begin{tabular}{lrr}
\hline Percentage of customers & $(1)$ & $(2)$ \\
\hline $0-10$ & 11,50 & 24,00 \\
$11-25$ & 15,50 & 16,00 \\
$26-50$ & 19,00 & 16,00 \\
$51-75$ & 20,00 & 15,00 \\
Above 75 & 34,00 & 29,00 \\
\hline
\end{tabular}

notes Column headings are as follows: (1) Grouper, (2) other deal platforms.

TABLE 4 Promotional Profitability by Featuring Deals on Grouper and Other Deal Sites, Evaluated by Companies (\%)

\begin{tabular}{lrr}
\hline How merchants characterise promotions' profitability? & $(1)$ & $(2)$ \\
\hline We spent significant amount of funds for the promotion & 3,92 & 12,50 \\
We spent small amount of funds for the promotion & 9,80 & 12,50 \\
We broke even & 23,53 & 32,14 \\
We made small profit through the promotion & 48,04 & 37,50 \\
We made substantial profit through the promotion & 14,71 & 5,36 \\
\hline
\end{tabular}

Notes Column headings are as follows: (1) Grouper, (2) other deal platforms.

service or product that anyway would pay full price, then it can produce cannibalization. $34 \%$ of participated companies answered that running group deal promotion on Grouper they offered their services mostly to new customers (over $75 \%$ were new). $88.5 \%$ of the respondents reported that they have over $10 \%$ new customers running promotion on Grouper vs. $76 \%$ running promotions on other group buying sites. Table 3 shows efficacy of the promotion in new customer acquisition on Grouper and on the other group sites.

Profitability of the deals output characteristics is also important factor of the probability that merchant will repeat the daily deal. Hypothesis $\mathrm{H} 1.1$ is supported at $10 \%$ significance level. Grouper promotions were profitable for $62,7 \%$ of the companies vs. 42 , and $9 \%$ of the companies running promotions on other group buying sites. Dholakia (2010) conducted a study of 150 businesses which had used a Groupon group buying deal. He found that the Groupon promotion was profitable for $66 \%$ of the study participants. Table 4 shows how survey participants evaluated promotion's profitability featuring deals on Grouper and other deal sites.

To make customers brought to the company' doors repeated or a reg- 
TABLE 5 Percentage of Repetition Customers Gained by Deal Promotion on Grouper and on the Other Group Sites (\%)

\begin{tabular}{lrr}
\hline Percentage of deal users that became repeat customers & $(1)$ & $(2)$ \\
\hline o & 8 & 21,00 \\
Up to 10 & 32 & 39,00 \\
$10-25$ & 27 & 16,00 \\
$26-50$ & 18 & 10,00 \\
Above 51 & 15 & 14,00 \\
\hline
\end{tabular}

NOtes Column headings are as follows: (1) Grouper, (2) other deal platforms.

ular customer is the most important benefit that companies can gain running group deal promotions. In essence, a price promotion succeeds when it entices new customers to try a particular offering through a compelling offer, and they like it so much that they buy it repeatedly, becoming the firm's relational customers (Dholakia 2006). Hypothesis $\mathrm{H} 1.2$ has ambiguous and statistically not significant impact on merchant's intention to repeat daily deal. $27 \%$ of the participants answered that in case of Grouper promotions they gained 10-25\% repeat customers and $18 \%$ managed to win repeat 26 to $50 \%$ customers. Table 5 shows percentage of repetition customers gained by deal promotion on Grouper and on the other group sites. $60 \%$ of the promotions on Grouper gained over $10 \%$ regular customers and $40 \%$ on the other sites.

Hypothesis $\mathrm{H} 1.5$ has ambiguous and statistically not significant impact on merchants' intention to repeat the daily deal. $64 \%$ of the respondents reported unredeemed coupons to $5 \%$ and the rest or $36 \%$ had unredeemed coupons over $5 \%$ of the purchased coupons. The unredeemed coupons' rate can be considered from 2 aspects. First the unredeemed coupons are direct profit from the promotion because the merchant receives payment for all coupons sold regardless of the redemption. Beside, after the redemption period the unredeemed coupons lose the promotional value but the buyer can use it for products or services for the price paid for the coupon or he can pay the difference in the price (the discounted amount) to get the product/service he firstly bought on a deal. Second, the unredeemed coupons should not be viewed as a profit because the company loses potential new customers that can become repeat customers with lifetime value. The question remains if the merchants feel that the unredemption rate has a positive or negative impact on the promotion.

The correlation of the firm characteristics with merchants' intention to 
repeat the offer to group buying site is positive by category of the companies. $\mathrm{H} 2.2$ is suported at $10 \%$ significance level. Other firms characteristics like number of employees, age, and type of promotion company does are ambiguous and $\mathrm{H} 2.1, \mathrm{H} 2.3$ and $\mathrm{H} 2.4$ do not statistically significant impact the intention on repetition of the daily deal.

Empirically, also, the effect is found to be positive on the coupons sold for the given promotion offered at group buying site, but does not statistically significant impact the intention to repeat the daily deal. As expected, discount on regular price is negatively but not statistically significant impacts the intention for daily deal repetition. $\mathrm{H} 3.1$ and $\mathrm{H} 3.2$ are not supported. This suggests that drivers that will push merchants to repeat the deals offeres are profitability, spending beyond the coupon, new customers brought in the company by the given promotion, and also intention is diverse among different categories of businesses.

\section{Limitations and Future Research}

To enable a correct interpretation of the study's results, it is important to acknowledge its limitations. Like any survey-based study, our results are susceptible to a non-response bias, i.e., the possibility that those who did not respond to our survey were systematically different from those that did participate. Response rate we obtained is $20 \%$. It is as well worth to be mention as limitation that the survey based methodology also means that all performance metrics are assessed based on self-reports provided by business decision makers. Such information is based on subjective assessments of respondents and may be inaccurate in reflecting actual customer behaviours. Nevertheless, since these individuals will make future decisions regarding daily deal promotions, it can be argued that their assessments, even though subjective, are what matters. Finally, we note that $55 \%$ of the companies offered deal on other sites like: Kupinapopust, Kupime, Kolektiva, Sakampopust etc., and we made comparison with all companies.

The findings that restaurants and retailers (store-fronts and offline) are having a more difficult time making daily deals work compared to other industries, can challenge the researchers for future work in this new group buying industry.

\section{Conclusion}

There are some suspicions in the literature regarding sustainability and future of group buying promotion, even though they gained great popu- 
larity. This study addresses the question of sustainability through investigation of merchant's intention to repeat the daily deals offers and gives important knowledge to understand the real potential associated with daily deal promotions to merchants. Even though group buying promotional tool, as every other promotion aims to drive store traffic and increase product demand and brand awareness, small and medium sized businesses in case of deal promotions also seek to generate residual benefits from the deal in the form of opportunities to gain profit, to upsell on regular price, to gain new customers and to keep them as repeat customers. The performance of group buying deals promotions using Grouper internal database and by conducting online survey was investigated. Strong support in the tobit model is given to spending beyond the coupon (h1.3), followed by new customers brought to the business (h1.4) and the profitability of the deals output (h1.1). Repeat customers and non-redemption was found to have ambiguous and statistically not significant impact on merchant's intention to repeat daily deal (h1.2 and h1.5). The correlation of the firm characteristics with merchants' intention to repeat the offer to group buying site is positive and statistically significant by category of the companies (h2.2), while other firms characteristics like number of employees, age, and type of promotion company does are ambiguous and statistically not significant (h2.1, h2.3 and h2.4). Number of sold coupons has positive, but statistically not significant impact on merchant's intention to repeat daily deal (h3.1), while discount on regular price has negative but statistically negative impact $\left(\mathrm{h}_{3.2}\right)$.

The findings of this study suggest that drivers that will push merchants to repeat the deals offers are spending beyond the coupon, new customers brought in the company by the given promotion, profitability, and also intention is diverse among different categories of businesses. The findings can be used by the group deal sites, so that they can advise merchants to make the deal attractive for the customers, so that the deal will reach more sales and on the other hand the merchant will be satisfied from the promotion, in order to become a repeating customer for the deal site. One suggestion is to design the deals in a manner that encourages cross selling. For example, for restaurants it is always better to offer food or package of food that is not including drinks so that the merchant makes a direct profit from the particular deal from the coupon customers. For beauty salons and spas it is better not to bundle many services in one package because this way the target of the potential customers is smaller and the merchant won't be able to do cross selling on other services. When 
it comes to cross selling it is an incentive to offer an extra discount for instance $20 \%$ discount on other services or products that are not included in the coupon in order to achieve cross selling. For example a restaurant promotion for launch package for 2 persons can favour a particular wine company by giving $20 \%$ discount on a bottle of with and the merchant can negotiate better prices with the wine producer for the cross selling promotion.

\section{References}

Anand, K. S., and R. Aron. 2003. 'Group Buying on the Web: A Comparison of Price-Discovery Mechanisms.' Management Science 49 (11): 1546-62.

Bazilian, E. 2011. 'Has the Daily Deals Market Reached Its Breaking Point?' http://www.adweek.com/news/technology/has-daily-deals-market -reached-its-breaking-point-134958

Bilinska-Reformat, K., and B. Reformat. 2011. 'Group Buying as a Source of Competitive Advantage of Polish Small and Medium-Sized Enterprises.' In Proceedings of 19th Annual Conference on Marketing and Business Strategies for Central and Eastern Europe, 3-19. Chicago: DePaul University; Vienna: University of Economics and Business Administration.

Blattberg, R. C., and S. A. Neslin. 199o. Sales Promotion: Concepts, Methods, and Strategies. Englewood Cliffs, NJ: Prentice Hall.

Byers, J. W., M. Mitzenmacher, and G. Zervas. 2012. 'The Group Effect on Yelp Ratings: A Root Cause Analysis.' In Proceedings of the 13 th ACM Conference on Electronic Commerce, 248-65. New York: ACM.

Cao, Z., K. L. Hui, and H. Xu. 2018. 'When Discounts Hurt Sales: The Case of Daily-Deal Markets.' Information Systems Research 29 (3). https://doi.org/10.1287/isre.2017.0772

Cremer, J. 1984. 'On the Economics of Repeat Buying.' RAND Journal of Economics 15 (3): 396-403.

Dholakia, U. M. 2006. 'How Customer Self-Determination Influences Relational Marketing Outcomes: Evidence from Longitudinal Field Studies.' Journal of Marketing Research 43 (1): 109-20.

- 2010. 'How Effective Are Groupon Promotions for Businesses?' Working Paper, Rice University, Houston.

Dong-Hun, L. 2009. 'Consumption Trends for 2009.' SERI Quarterly 2 (1): $100-5$.

Erdogmus, I. E., and M. Cicek, 2011. 'Online Group Buying: What Is There for the Consumers?' Procedia: Social and Behavioral Sciences 24 (15): 308-16.

Geron, T. 2011. 'First Facebook, Now Yelp Scaling Back Daily Deals.' http:// www.forbes.com/sites/tomiogeron/2011/o8/30/first-facebook-now 
-yelp-scaling-back-daily-deals-report

Grandhi, S., G., R. Chugh, and S. Wibowo. 2016. 'An Empirical Study of Customers' Purchase Intentions from Australian Group Buying Sites.' Journal of Internet and e-Business Studies. https://ibimapublishing.com/ articles/JIEBS/2016/732154/732154.pdf

Greene, W. H. 2003. Econometric Analysis. Upper Saddle River, NJ: Prentice Hall.

Greenleaf, E. A. 1995. 'The Impact of Reference Price Effects on the Profitability of Price Promotions.' Marketing Science 14 (1): 82-104.

Gupta, S., R. Weaver, T. Keiningham, and L. Williams. 2012. 'Are Daily Deals Good for Merchants?' Harvard Business School Background Note 513-059, Boston, MA.

Guy, S. 2012. 'Groupon Founders Tally Billions in Paper Losses.' http://www .suntimes.com/business/12998739-420/groupon-founders-tally-billionsin-paper-losses.html

Heussner, Ki M. 2012. 'Closure of CityPockets Provides Window onto Shakeout in Daily Deal Business.' http://gigaom.com/2012/05/10/ closure-of-citypockets-provides-window-onto-shakeout-in-daily-deal -business/

Kamenec, K. 2012. 'Travelzoo Ceo Chris Loughlin, Bases Daily Deal Industry Dynamics.' http://www.dailydealmedia.com/724travelzoo-ceochris-loughlin-bashes-daily-deal-industry-dynamics/.

Kauffman, R. J., and B. Wang. 2001. 'New Buyer's Arrival under Dynamic Pricing Market Microstructure: The Case of Group Buying Discounters on the Internet.' Journal Management INFORM Systems 18 (2): 15788 .

- 2002. 'Bid Together, Buy Together: On The Efficacy Of GroupBuying Business Models In Internet-Based Selling.' Paper presented at the 5th Annual University of Minnesota Electronic Commerce Conference, 27-28 March, Minneapolis, MN.

Kotecha, A. A., J. Leibowitz, and I. MacKenzie. 2008. 'How Retailers Can Make the Best of a Slowdown.' McKinsey Quarterly no. 4: 104-7.

Kotler, P., and G. Armstrong. 2009. Principles of Marketing. Upper Saddle River, NJ: Prentice Hall.

Li, S. 2012. 'Groupon Faces Growing Doubts about Its Credibility and Viability.' http://articles.latimes.com/2012/apr/o6/business/la-fi-groupongrowing-pains-20120407

Mazen, A. 2012. 'Groupon's Biggest Obstacle Is Merchant Retention.' http:// seekingalpha.com/article/317246-groupon-s-biggest-obstacle-is -merchant-retention

Narasimhan, C. 1984. 'A Price Discrimination Theory of Coupons'. Marketing Science 3 (2): 128-47. 
Nelson, P. 1970. 'Information and Consumer Behavior.' Journal of Political Economy 78 (2): 311-29.

- 1974. 'Advertising as Information.' Journal of Political Economy 82 (4): 729-54.

Reisinger, D. 2011. 'Struggling BuyWithMe May Live on as Unit of Gilt, Report Says.' http://news.cnet.com/8301-13506_3-20127170-17/strugglingbuywithme-may-live-on-as-unit-of-gilt-report-says/

Sherr, I. 2010. 'Online Coupons Get Smarter - Groupon, Rivals Add Personalized Bargain Staff as Some Merchants Gripe.' Wall Street Journal, 25 August.

Stulec, I. and K. Petljak. 2010. 'Moc grupne kupovine'. Suvremena trgovina 35 (6): 22-5.

Stulec, I., K. Petljak, and R. Vouk. 2011. 'The Role of Internet in Empowering Consumers: The Case of Group Buying.' In Proceedings of MSKE 2011: Managing Services in the Knowledge Economy, 730-41. Largo Tinoco de Sousa: Universida de Lusíada de Villa Nova de Famalicão.

Subramanian, U., and R. C. Rao. 2016. 'Leveraging Experienced Consumers to Attract New Consumers: An Equilibrium Analysis of Displaying Deal Sales by Daily Deal Websites.' Management Science 62 (12): $3555-75$.

Taulli, T. 2012. 798 'Daily-Deal Sites Die - in 6 Months.' http://www .investorplace.com/ipo-playbook/798-daily-deal-sites-die-in-6 -months/

TechCircle. 2013. 'Lack of Merchant Focus Tripped up Indian Group Buying Sites: Groupon India CEO AnkurWarikoo.' http://techcircle .vccircle.com/2013/o3/26/lack-of-merchant-focus-tripped-up-indiangroup-buying-sites-groupon-india-ceo-ankur-warikoo/

Vacanti, V. 2011. 'Is Groupon Bad for Small Businesses?' http://techcrunch .com/2011/o7/o2/groupon-small-businesses/

Varian, H. R. 1980. 'A Model of Sales.' American Economic Review 70 (4): 651-9.

Walters, R. G., and S. B. MacKenzie. 1988. 'A Structural Equations Analysis of the Impact of Price Promotions on Store Performance.' Journal of Marketing Research 25(1): 51-63. 